\title{
BRIÓFITAS RUPÍCOLAS DE UM TRECHO DO RIO BETHARY, IPORANGA, ESTADO DE SÃO PAULO
}

\author{
Sandra Regina Visnadi (1) \\ Daniel Moreira Vital (2)
}

\begin{abstract}
RESUMO - Foram encontradas 19 espécies de briófitas, sendo 14 espécies de musgos e 5 espécies de hepáticas, cobrindo uma maior extensão de rochas das margens que do centro do leito do rio. As rochas das margens do rio, bem iluminadas, porém sem receber luz direta do sol, apresentaram uma maior número de espécies, muito emaranhadas entre si. Já as rochas do centro do leito do rio, iluminadas pela luz direta do sol, apresentaram um menor número de espécies, formando tufos isolados ou pouco emaranhados entre si.
\end{abstract}

Palavras-chaves: Briófitas rupícolas, Rio Bethary, Iporanga/SP.

\begin{abstract}
Nineteen species of bryophytes were found being 14 species mosses and 5 species liverworts. These plants occured in greater extension on the rocks of the riverbank than on the rocks of riverbed. The rocks on the riverbank which received indirect sun light showed a larger number of species very entangled among themselves. The rocks of the riverbed which received direct sun light showed a smaller number of species forming isolated turfs or were nor very entangled among themselves.
\end{abstract}

Key-words: Rupicolous bryophytes, Bethary river, Iporanga/SP.

\section{Introdução}

Muitos estudos têm sido feitos sobre a ecologia de briófitas de regiões temperadas e polares desde a publicação do capítulo Bryo-cenology por $\mathbf{H}$. Gams e do capítulo Ecology por P. W. Richards no Manual of Bryology editado por F. Verdoorn em 1931, mas relativamente pouco progresso tem sido alcançado no estudo da ecologia de briófitas tropicais (Richards, 1984).

(1) Estagiária da Seção de Briologia e Pteridologia, aluna de Pós-Graduação, UNESP, Rio Claro - SP. Bolsista da CAPES (Solicitação de Cópias).

(2) Seção de Briologia e Pteridologia, Instituto de Botânica, Caixa Postal 4005, CEP 01051 - São Paulo - SP. Brasil. 
Isto é conseqüência do pequeno entendimento da taxonomia de briófitas tropicais (Schuster, 1983) e do conhecimento sobre a ecologia de briófitas de regiōes tropicais, exceto sobre o grupo das briófitas que crescem como epífilas sobre folhas vivas, se basear em observações fragmentárias desde 1929. A partir de 1950, a situação melhorou um pouco, pois surgiram alguns trabalhos sobre ecologia de briófitas da Ásia, Porto Rico e África (Richards, 1984).

O primeiro trabalho sobre a ecologia de briófitas no Brasil foi feito por R. C. L. Lisboa em 1976, abordando a ecologia das briófitas amazônicas, e apesar da inexistência de trabalhos sobre a ecologia de briófitas rupícolas brasileiras, sabe-se que estas plantas são importantes na retenção de partículas trazidas pela correnteza, além de evitar a erosão do substrato através do impacto da água (Ando \& Matsuo, 1984).

O presente trabalho tem por objetivos o conhecimento das espécies de briófitas rupícolas de um trecho do Rio Bethary e a associação da variação da composição da brioflora nas diferentes condições de luminosidade e umidade atuando sobre este substrato.

\section{Material e Métodos}

O material foi coletado em rochas emergentes das margens e do centro de um trecho ro Rio Bethary, próximo à Caverna do Santana, localizado no Parque Estadual e Turístico Alto Ribeira - PETAR, município de Iporanga, estado de São Paulo. A localização geográfica é $25^{\circ} 32$ 'S e $48^{\circ} 42^{\prime} \mathrm{W}$.

As coletas foram realizadas em outubro de 1988. O material foi identificado com o auxílio de chaves de identificação de Evans(1907), Bartram (1949), Heil (1969), Saito (1975), Fulford (1976), Gier (1980) e Schuster (1980). As exsicatas se encontram depositadas no herbário da Seção de Briologia e Pteridologia do Instituto de Botânica em São Paulo (SP).

\section{Resultados}

Foram encontradas, de acordo com a tabela 1, 19 espécies de briófitas, sendo 14 espécies musgos e 5 espécies de hepáticas.

Quanto a variedade de espécies, verificou-se que as rochas das margens, bem iluminadas, porém sem receber luz direta do sol, apresentaram um maior número de espécies geralmente muito emaranhadas entre si. As rochas do centro do leito do rio, iluminadas pela luz direta do sol, apresentaram um menor número de espécies, formando tufos isolados ou pouco emaranhados entre si.

Em relação à cobertura do substrato pelas plantas, as margens sombreadas apresentaram uma maior extensão de rochas cobertas pelas briófitas que o centro do leito do rio.

A iluminação foi um fator importante na distribuição das briófitas, pois as rochas das margens iluminadas pela luz direta do sol, apresentaram a mesma composição de briófitas e associação entre as espécies que as rochas do centro do leito do rio. 
Em relação à umidade, pode-se verificar que a água é percolante entre a planta e o substrato para as espécies de briófitas que ocorrem exclusivamente ou preferencialmente nas margens sombreadas do rio. Para as briófitas que ocorrem exclusivamente ou preferencialmente no centro do leito do rio, bem como as que ocorrem indistintamente no centro e nas margens sombreadas e ensolaradas, a água cobre quase totalmente a planta (Fissidens asplenoides Hedw. e Platyhypnidium aquaticum (Jaeg.) Fleish.), ou a planta fica totalmente exposta, recebendo apenas esporadicamente gotículas de água (Hyophila involuta (Hook.) Jaeg. e Sematophyllum ripariodes Bartr.), com exceção de Marchenisia brachiata (Sw.) Schiffn. na qual a água aparece percolante entre a planta e a rocha.

\section{Conclusōes}

Os resultados demonstram que a maior parte das espécies prefere o ambiente bem iluminado, porém sem receber luz direta do sol.

Por outro lado, apenas algumas espécies parecem preferir o ambiente bem iluminado pela luz direta do sol como Hyophila involuta (Hook.) Jaeg., Platyhypnidium aquaticum (Jaeg.) Fleish. e Sematophylum ripariodes Bartr.. Já outras se desenvolvem tanto em ambientes sombreados como ensolarados como Marchesinia brachiata (Sw.) Schiffn. e Fissidens asplenoides Hedw.

Com relação a umidade, as briófitas parecem ocorrer em rochas das margens onde a água aparece percolante entre a planta e o substrato. Já as espécies de briófitas do centro do leito do rio parecem ocorrer geralmente em porções das rochas totalmente emergentes ou quase totalmente cobertas pela água.

\section{Referências Bibliográficas}

ANDO, H. \& MATSUO, A. 1984. Applied Bryology. Advances in Bryology, 2: 133-224. BARTRAM, E. B. 1949. Mosses of Guatemala, Fieldiana, Bot. 25: 442p..

EVANS, A. W. 1907. Hepaticae of Puerto Rico VIII. Symbiezidium, Marchesinia, Mastigolejeunea, Caudalejeunea, and bryopteris . Bull. Torrey bot. Cl. 34(11): 533-578.

FULFORD, M. H. 1976. Manual of the Leafy Hepaticae of Latin america. Mem. N. Y. bot. Gdn. 11(4): 393-535.

GIER, L. J. 1980. A preliminary study of the Thuidiaveae of Latin America. J. Bryol. 11(2): 253-309.

HELL, K. G. 1969. Briófitas talosas dos arredores da cidade de São Paulo (Brasil). Universidade de São Paulo. Boletim no 335, Botânica no 25, 187p.

LISBOA, R. C. L. 1976. Estudos sobre a vegetação das campinas amazônicas. V - Brioecologia de uma campina amazônica. Acta Amazônica, 6(2): 171-191.

RICHARDS, P. W. 1984. The Ecology of Tropical forest bryophytes. In: Schuster, R. M., New Manual of Bryology. J. Hattori bot. Lab., v.2, p. 1232-1270.

SAITO, K. 1975. A monograph of Japanese Pottiaceae (Musci), J. Hattori bot. Lab. 39: 373-537.

SCHUSTER, R. M. 1980. The Hepaticae and Anthocerotae of North America. Columbia University Press, v. 4, 1334 p.. 
. 1983. Phytogeography of the Bryophyta. In: Schuster, R. M., New Manual of Bryology. J, Hattori bot. Lab., v.1, p. 463-626. 
Briófitas rupícolas de um trecho...
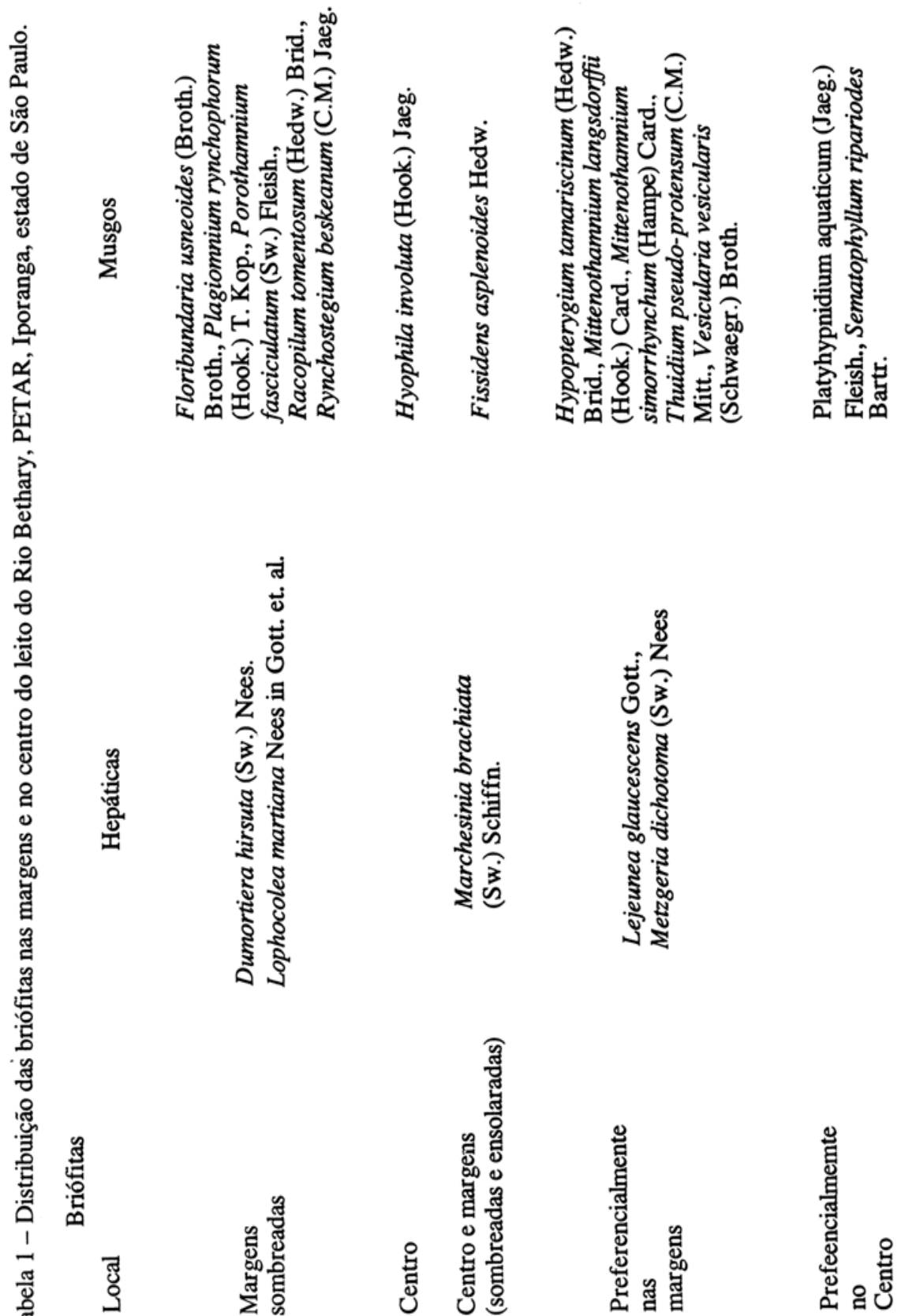